Article

\title{
Sustainability Determinants of Cultural and Creative Industries in Peripheral Areas
}

\author{
Francesca Imperiale *, Roberta Fasiello and Stefano Adamo
}

check for updates

Citation: Imperiale, Francesca, Roberta Fasiello, and Stefano Adamo. 2021. Sustainability Determinants of Cultural and Creative Industries in Peripheral Areas. Journal of Risk and Financial Management 14: 438. https://doi.org/10.3390/ jrfm14090438

Academic Editor: Daniela Angelina Jelinčić

Received: 2 August 2021

Accepted: 2 September 2021

Published: 10 September 2021

Publisher's Note: MDPI stays neutral with regard to jurisdictional claims in published maps and institutional affiliations.

Copyright: (c) 2021 by the authors. Licensee MDPI, Basel, Switzerland. This article is an open access article distributed under the terms and conditions of the Creative Commons Attribution (CC BY) license (https:/ / creativecommons.org/licenses/by/ $4.0 /)$.
Dipartimento di Scienze dell'Economia, University of Salento, 73100 Lecce, Italy; roberta.fasiello@unisalento.it (R.F.); stefano.adamo@unisalento.it (S.A.)

* Correspondence: francesca.imperiale@unisalento.it; Tel.: +39-329-311-5089

\begin{abstract}
Cultural and Creative Industries (CCIs) are increasingly recognized as part of the global economy and of growing importance for sustainable local development. However, the exploitation of their full potential depends on several issues concerning their entrepreneurial dimension and the context where they operate. The paper deals with these issues having the scope to investigate the main determinants of CCIs' sustainability in peripheral areas, to understand what kind of policy could better support the survival of CCIs and development in these areas, according to an end-user perspective. The research is part of an Interreg Greece-Italy project carried out from mid-2018 until the end of 2020 with specific reference to CCIs in Apulia (IT) and Western Greece (EL). A two-step mixed methodology has been used to figure out regional specializations and the specific aspects of the entrepreneurial structure and business sustainability in the cultural and creative sector (CCs). In the end, the paper shows and discusses the main determinants considered crucial for CCI sustainability, suggesting guidelines for local authorities supporting their economic development.
\end{abstract}

Keywords: cultural and creative industries; sustainability; peripheral areas

\section{Introduction}

CCIs (Cultural and Creative Industries) are diverse, literature and policy setters have proposed different models to be identified, mapping activities and their potentialities (see the overview in Boffo and Chizzali 2015). Indeed, delimiting the activities falling within CCs (Cultural and Creative sector) is not an easy operation if we also consider the fact that it is a rapidly evolving sector, strongly influenced by technology and by the processes leading to content and products (on the cultural and creative industries history see O'Connor 2000, O'Connor [2007] 2010).

All around the world, the CCs is a major and growing part of the global economy. Its importance as a generator of jobs and wealth is increasingly recognized (EY 2015; United Nations/UNDP/UNESCO 2013). Indeed, the latest study of the EIF market at the European level (European Investment Fund 2019) finds that the CCs represents a significant share of the European economy which accounts for over $4 \%$ of the Union's GDP, ensuring employment to 6.7 million people, mostly young people. Furthermore, the number of CCs enterprises (CCIs) has grown by $4.3 \%$ every year since 2008 , and today it represents $10 \%$ of the service sector in most European countries. Employment, which has remained stable overall since 2008 , has grown by $1 \%$ annually, but in some sectors, such as audiovisual and media, it has increased by $3 \%$. For their contribution to creativity, CCIs also have a positive impact on other sectors, including in particular consumer electronics, telecommunication services, and tourism.

Moreover, research clearly agrees on the fact that CCIs are of growing importance for sustainable urban development and inclusive growth (e.g., Hall 2000; Heebels and van Aalst 2010; Power 2003; Pratt 2010; Skoglund and Jonsson 2012; Flew 2012; Correa-Quezada et al. 2018; Lazzeretti and Vecco 2018; UNESCO-World Bank 2021). Various studies show 
a wide range of effects and spillovers that they are able to generate for the benefit of territories and society (Tom Fleming Creative Consultancy 2015; McNeilly 2018).

Thus, as far as policy-making is concerned, culture and creativity are receiving growing attention as important developmental factors. Developing CCIs has been considered an opportunity for local attractiveness, economy, and social wealth, and unlocking their potential is quickly becoming a priority of public policies, at least in Europe (Executive Agency for Small and Medium-sized Enterprises of the European Commission 2016).

Indeed, in this attempt of culture and creative instrumentalism (Gray 2007), policymakers have turned to 'fast policy' (Peck 2005), which Pratt (2009) names 'Xerox policy making': "policies that are simply copied with little or no variation from one place to another with no acknowledgment of the different social and economic contexts, and little attention to the policy object".

Indeed, governments are putting in place strategies to promote and support the development of CCIs at the local level, which denotes such a character, as Foord's study (Foord 2008) shows. Apart from various notional and classificatory policy inconsistencies and confusion-which also other studies well put in evidence (i.e., Cunningham 2002; Hesmondhalgh and Pratt 2005; Galloway and Dunlop 2007), he identified broad categories of intervention which are similar to generic business support initiatives, mostly converging in Porterian-like business cluster strategies at the local level.

On the point, there is no lack of criticism about the main conceptual models actually inspiring the policy-making in the field, mainly Florida's creative class approach (Florida 2002, 2005) and Porter's theory of competitive advantage (Porter 1989). Sacco et al. (2014), in their meta-analytic review of the literature on culture-led development models, shed light on the typical fallacies of these approaches, remarking the opportunity to not generalize according to a linear and mono-causal scheme. Rather, they claim for fleshing a "new territorial thinking" that builds frameworks upon the diverse and interacting conditions under which "culture works as an economically effective, socially sustainable developmental factor" (Sacco et al. 2014, p. 2807).

It is well acknowledged that the capacity of CCIs "to result in economically sustainable cultural enterprises" (Kavousy et al. 2010), and thus to benefit territories, depends on several factors.

Firstly, there are important factors related to their entrepreneurial dimension which preventing them from exploiting their full potentialities and limiting the positive influence they could have on the overall economy (Executive Agency for Small and Medium-sized Enterprises of the European Commission 2016). CCIs have specific characteristics, which make them very different from enterprises operating in other sectors (Caves 2000), making challenging the policy-making in the field (Pratt 2012). Although, some other consider this emphasis on such a difference erroneous or undue (Townley et al. 2009).

In the reviewed literature (Caves 2000; Pratt 2009; HKU 2010; Borisova 2018; Lazzaro 2018; Madgerova and Kyurova 2019), these features mainly identified four broad characteristics that would demand a different order of managerial and organizational challenges: the nature of the product, the size, the organizational structure, and the entrepreneurial character.

Compared to other types of goods, cultural and creative works encompass nonutilitarian values, such as aesthetic, spiritual, social, historical, symbolic qualities (Throsby 2001, pp. 28-29). Thus, their utility depends on the consumer's coding and decoding of value (Hall 1973), and this raises uncertainty both in the process and in the market (Townley et al. 2009).

Then, the so-called 'missing middle': enterprises are either 'big players' (very large multinationals) or micro and small organizations, the latter being the majority, that may also operate in the not-for-profit form or as social enterprises, often as freelancers. These are activities that can operate in a range of formal and informal, for-profit and not-for-profit, state and commercial activities, and between production and consumption, often resulting in interdependency in their work (Pratt 2009). 
Moreover, CCIs are usually provided with a temporary (i.e., not permanent) workflow (Benhamou 2003), together with a project-based prototyping structure (DeFillipi and Arthur 1998). Indeed, CCIs put in place a creative process that is shaped by the inspiration, talent, vitality, and commitment of cultural and creative workers, coming out from complex knowledge and operational flows, which make working in these enterprises highly volatile (Leadbeater and Oakley 1999). In this regard, Jeffcutt and Pratt (2002) defined CCIs as "chart businesses", to highlight that they assume "different organizational forms at different times and for different technologies and industries", and they are "very good at producing products and markets for novelty" (Jeffcutt and Pratt 2002, p. 8).

Finally, there is a general lack of entrepreneurial skills within all sectors of the CCIs (HKU 2010; ArtENprise 2016). Creative people lack the resources to turn their innovative ideas into viable business propositions. They often find it hard to establish trusted relationships with each other as well as with HE\&R (Higher Education and Research) institutes. What is more, is that they often show inadequacy in network competency, which, instead, is a fundamental element to increase cross-sectoral expertise and to foster cross-cutting opportunities. As a result, CCIs are often isolated, facing the difficulty of developing sustainable structures and of gaining market visibility, which leads to the ultimate challenge of achieving investments.

However, to what extent these features hinder or promote the CCIs sustainability is controversial. On the one hand, the small size and precariousness of cultural workers obviously pose important sustainability challenges. On the other hand, these are determinants in forging CCIs innovativeness, thanks to the interactive learning induced by the creative workers' mobility in various projects and teams (Falk et al. 2011), as well as the CCIs capacity to resist changes induced by economic crisis compared to the performance of other sectors (Harc et al. 2019).

Literature highlights relevant location factors acting as CCIs development drivers, as well. Because of their inherent features, CCIs normally tend to locate their business in large urban agglomerates, to the detriment of peripheral areas where they are unable to find the ideal conditions for start-up and growth. Although, according to a divergent position, the location outside the "creative hub" could sometimes bring other advantages in terms of personal attachment and social embeddedness of creative individuals, lower overhead and running costs, local networking, and support (Chapain and Comunian 2010; Comunian et al. 2010).

According to the literature review made by Gong and Hassink (2017), with an economic geography perspective, there would be three complementary location drivers in CCIs' tendency to cluster in specific places: agglomeration economies, spin-off formations, and the institutional environment. On these drivers, it follows a summary of their main findings and related quoted literature (Gong and Hassink (2017), pp. 6-13).

As mentioned above, CCIs tend to concentrate their businesses in places offering agglomeration economies with specific characteristics or large cities and metropolises (Chapain and De Propris 2009; Lorenzen and Frederiksen 2008), profiting from localization (Branzanti 2015; O'Connor 2004; Storper 1995; Lazzeretti et al. 2008) or urban economies (Florida 2002, 2005; Landry 2008).

In certain areas and for specific CCIs, spin-off activities conducted by Universities and Art Schools (Rantisi and Leslie 2015; Wu 2005) or other companies (Wenting 2008; De Vaan et al. 2013) are determinant spatial patterns that emphasize the importance of knowledge transfer between parent organizations and creative spin-off firms.

The CCIs concentration in certain places or regions depends on the formal and informal institutional environment, which is another location factor particularly crucial for the CCIs' development at all scales. On a formal level, the significant forces are the existence of institutional support, the public-private partnerships and training organizations (Scott 2000; Harvey et al. 2012; Turok 2003), as well as the presence of various kinds of intermediaries (Jakob and van Heur 2015) acting as brokers in facilitating networking among CCIs. In addition, the existence of trust, and norms and values shared by community 
members, a favorable institutional climate are other informal factors, which qualify the institutional environment as a driving force in the CCIs location choice (Florida 2002, 2005; Landry 2008; Wenting and Frenken 2011).

However, it is not the case for all CCIs businesses. For instance, taking into account, the internal heterogeneity of the CCs, Tomczak and Stachowiak (2015) observed two different CCIs location patterns that might coexist in the same area. On one side, the spatial behavior of production-related industries (those involved in specialized production or publishing, computer games, the production of TV programs, and video recording), which show a strong tendency to gather in some areas and form clusters, both at global and lo$\mathrm{cal} /$ regional scale. On the other side, consumer-oriented or final-user industries (those closest to the consumer in the value chain: exhibition rooms and theatres, or business-related services like photography, advertising, architecture, etc.) which tend to be distributed fairly evenly in space, with a general tendency to concentrate where the population has reached a certain number making it payable to locate an activity there.

Overall, this tendency of CCIs to cluster in specific areas generates spatial disparities among regions aiming at culture-led development policies. Boal-San Boal-San Miguel and Herrero-Prieto (2020) examined CCI sector location patterns in Spain from a spatialtemporal perspective showing that "areas closest to creative clusters and urban nucleuses are those that benefit most from CCI growth due to spillover effects and spatial dependence while in peripheral regions this phenomenon is not observed. This means that spatial disparities exist and are also reinforced over time, along the line of the consequences of technological gap models" (Boal-San Miguel and Herrero-Prieto 2020, p. 15). This empirical evidence highlights the risk of the so-called Xerox policy-making (Pratt 2009), suggesting that CCIs might not be engines of growth everywhere and that "the CCI(s) have a number of specific aspects that require dedicated policy-making" (Pratt 2009, p. 11; 2012).

Thus, effective policy-making aiming at supporting CCIs cannot ignore an in-depth understanding of the main determinants of their business sustainability.

This paper addressed these issues as part of a wider applied research project, namely the "TRACES-Transnational Accelerator for a Cultural and creative EcoSystem". It is a project funded by the INTERREG GREECE-ITALY 2014-2020 program, priority axis 1"Innovation and Competitiveness", having the specific objective to support the incubation of innovative specialized micro and small enterprises in the Cultural and Creative Sector in Apulia (IT) and Western Greece (EL).

The overall aim of the paper is to explore the main factors that affect the CCIs capacity to result in economically sustainable enterprises in these peripheral European regions, to understand what kind of policy could better support CCIs survival and development in these areas. To this end, it used an end-user perspective, according to a participatory and tailored approach.

Thus, the main research questions addressed in the paper are: What are the main determinants, which CCIs consider crucial for their sustainability in these Regions? What kind of support do they need to survive, develop and produce benefits for territories?

The paper is structured as follows. Section 2 presents the research design and the methodology; Section 3 describes the main results, and Section 4 offers a discussion of these results according to the literature review and presents the main policy implications. In this regard, the paper contributes to a better understanding of policy-making for CCIs, suggesting the evidence-based and participatory approach as a useful methodology to customize the generic business support initiatives. Finally, Section 5 concludes the paper, pointing out that CCIs sustainability depends on several factors which contextual research could help to identify serving better policy design, being aware that CCIs present some peculiarities and that "copying" or "one size fits all" approaches might not work in this field. Future research agenda in the cultural management field is also suggested. 


\section{Materials and Methods}

As already mentioned, the research focuses on CCIs operating in Apulia, which is a region in Southern Italy, and in Western Greece, is one of the thirteen administrative units of Greece.

Both Regions share some characteristics, i.e., geographic remoteness, weak economies, out-migration, lack of control over decision-making processes, high aesthetic values, etc., and can be defined as peripheral areas, considering the distance from major dominant economic centers at the National and European levels. In addition, in the European Regional policy, both Regions are included in the Convergence Objective, which considers additional investments for Regions with per capita GDP at less than $75 \%$ of the Community average.

In this context and in consideration of the literature review, the main research aim is to identify the determinants of the CCIs sustainability in these areas according to a crossborder and participatory approach. The results inform the subsequent policy design in the investigated areas.

For the purpose of this research, the CCs perimeter has been defined according to the Italian monitoring system based on the Symbola and Unioncamere model (Symbola and Unioncamere 2013-Appendix A), and a two-step methodology has been used.

Firstly, according to the main approaches actually in use in both Countries to map CCIs, the research aims at identifying the cultural and creative specialization in both Regions, highlighting potential similarities. The research is based on an extensive collection of data provided by the Chambers of Commerce of both Regions. Data have been subjected to a prior normalization process in order to assure pertinence to the sector and comparability between the two territories. The data elaboration concerns the descriptive statistics of the CCIs population in terms of the number of companies, jobs, localization, and legal form. Further data processing has been necessary to calculate and visualize the localization index of each branch in the CCs, representing the territorial specialization according to a cross-border approach.

In the second phase, the focus groups technique was used in order to deepen specific aspects of the entrepreneurial structure and business sustainability of the mapped enterprises. Six focus groups, involving about 80 Apulian enterprises and 34 Western Greek enterprises, took place to collect relevant data, which has been subjected to a secondary analysis using a descriptive statistical approach. The sample consists of 28 companies operating in the Books and printing subsector; 15 companies operating in the Videogames and software branch; 13 organizations operating in Film, video, radio and TV subsector; 27 creative industries; 4 companies in the Music sector; 24 organizations in the Performing Arts and Heritage sector; 3 companies performing interdisciplinary activities.

Focus groups were conducted according to a semi-structured interview based on the Hogeschool vor de Kunsten Utrecht methodology (HKU 2010). Based on this methodology, a questionnaire was prepared, including eight different informative sections for a total of 78 questions for six thematic areas of investigation: access to finance; access to market; IPR instruments; entrepreneurship education, skills, and training; access to innovation; collaboration.

In the end, evidence from those two steps has been discussed with more than 400 CCIs and professionals located in various geographical zones of both Regions during 22 participatory meetings held according to the World Café methodology.

The research period goes from mid-2018 up to the end of 2019.

\section{Results}

The mapped enterprises belong to the following sectors: Cultural industries (Publishing, Music, Film, Video, Radio and TV, and Video Games), Creative industries (Architecture, Design, and Communication and branding), Performing Arts (Theater, Dance, Recreational activities, and Event organization) and Heritage (Museums, Archives, Libraries, and related services). 
The mapping and the analysis of collected data have made it possible to identify the cross-border specializations in the CCs, together with the main features of the entrepreneurial dimension of activities and the common challenges to growth.

\subsection{Regional Specialization in the Cultural and Creative Sector}

The mapped enterprises operating in the sector in both regions are 16.961: 13.602 of them are located in Apulia, while 3.359 are located in Western Greece.

The difference between CCIs in Apulia and Western Greece is not only numerical. As stated in previous studies, it also concerns their contribution to the local economy.

In Apulia, CCIs value-added amounts to $€ 2.7$ billion, namely $4.2 \%$ of the regional GDP, with an employment rate of 4.3\% (59.859 employees) (Fondazione Symbola 2019). In Greece, more than 30.000 cultural and creative enterprises are located in the Attica region (Avdikos 2014). These companies produce 75.5\% of the sector's GDP throughout Greece with an employment rate equal to $60.8 \%$ of the total workforce in the sector. This goes to the detriment of Western Greece, where CCIs only produce $0.6 \%$ of the Regional GDP and $1.8 \%$ of employment in the Region (Avdikos et al. 2017; Regional Development Fund of Region of Western Greece 2018).

Table 1 shows the subsector breakdown of the mapped enterprises, based on data provided by the Chambers of Commerce in both Regions.

Table 1. Number of the mapped enterprises in CCs in Apulia and Western Greece.

\begin{tabular}{lcc}
\hline Sector/Subsector & Apulia & Western Greece \\
\hline Creative Industries & $\mathbf{5 . 1 6 2}$ & $\mathbf{6 4 0}$ \\
\hline Architecture & 2.414 & 40 \\
\hline Communication and branding & 2.058 & 572 \\
\hline Design & 690 & 28 \\
\hline Cultural Industries & $\mathbf{7 . 5 5 2}$ & $\mathbf{2 . 4 7 8}$ \\
\hline Film, video, radio, and tv & 645 & 205 \\
\hline Software and videogames & 1.282 & 495 \\
\hline Music & 168 & 149 \\
\hline Books and printing & 5.457 & 1.629 \\
\hline Performing Arts & $\mathbf{8 2 2}$ & $\mathbf{2 3 3}$ \\
\hline Heritage & $\mathbf{6 6}$ & $\mathbf{8}$ \\
\hline Total & $\mathbf{1 3 . 6 0 2}$ & $\mathbf{3 . 3 5 9}$ \\
\hline
\end{tabular}

Table 1 clearly shows how in both Regions the Cultural Industries sector was the most populated and, within it, the sub-sector Books and printing concentrates the majority of enterprises working in this sector. In second place, we found the Creative Industries sector with the Communication and branding subsector representing the main specialization in both territories. Available data did not allow for a proper representation of the Performing Arts and Heritage sectors. Based on the direct observation and personal knowledge of the authors and TRACES partners, in these sectors, most enterprises are not registered at the Chamber of Commerce, considering that they usually are public companies or operate in the form of associations without a VAT number.

It follows the description of the main location patterns emerging from the mapping of CCIs in the cultural and creative industry sectors, applying the localization index on the raw data collected from the registers of Chambers of Commerce.

\subsubsection{Cultural Industries in Apulia and in Western Greece}

This sector includes companies operating in the following subsectors: Books and printing; Film, video, radio and TV; Music; Videogames and software. 
Table 2 shows the activities that in both Regions enroll the highest number of active enterprises.

Table 2. Cross-border specialization in the Cultural Industries sector.

\begin{tabular}{|c|c|c|}
\hline Subsectors & NACE Code & Activities \\
\hline \multirow{3}{*}{ Film, video, radio, and tv } & 59.11 & $\begin{array}{l}\text { Motion picture, video, and } \\
\text { television program }\end{array}$ \\
\hline & 60.10 & Radio broadcasting \\
\hline & 60.20 & $\begin{array}{l}\text { Television programming and } \\
\text { broadcasting activities }\end{array}$ \\
\hline \multirow{2}{*}{ Videogames and Software } & 58.21 & Publishing of computer games \\
\hline & 63.12 & Web portals \\
\hline \multirow{2}{*}{ Book and Printing } & 18.14 & Binding and related services \\
\hline & 74.30 & $\begin{array}{l}\text { Translation and interpretation } \\
\text { activities }\end{array}$ \\
\hline
\end{tabular}

Figure 1 reports the GIS maps of the mapped enterprises in these subsectors, offering a visual representation of their localization.

From Figure 1, we can observe different location patterns across subsectors and Regions.

In relation to the subsector Film, video, radio, and TV, the areas in the Apulia Region with the greatest presence of companies are the central Adriatic ones. In particular, the area of the Metropolitan City of Bari (5) and the area of Murgia dei Trulli (7) were identified as the two geographical zones in which these activities converge, even if the Tavoliere (3) and Magna Grecia (8) areas also showed high levels of entrepreneurial concentration in this subsector. The map of Western Greece, on the other hand, showed the greatest convergence of companies in the Ileia and Aitolokarnania units, particularly Ilida (264) in the former and Amfiloxia (260) and Agrinio (257), in the latter. In Western Greece, the spatial distribution of the companies operating in this subsector also showed the tendency to gravitate around the capital city of the Region (269-Patras).

This tendency to concentrate in the central zones of both Regions or to gravitate around the capital city was more evident for companies operating in the Videogames and software subsector. In Apulia, they were concentrated in the area of the Metropolitan City of Bari (5) and in the area of Lecce (11), the latter being the second important city of the Region, behind the capital city (Bari). Again Magna Grecia (8) and Alta Murgia (6) follow these two areas. The areas of Western Greece with the highest presence of companies producing video games and software are Pineios (270) and Nafpaktia (267).

Companies in the Books and printing subsector presented a different location pattern. In Apulia, they were predominant in the extreme North of the Region and the extreme South, mainly in the territorial areas of Gargano (1) and Monti Dauni (2), Arco Ionico (12), and Serre Salentine (13). In the biggest urban agglomerates (Bari and Lecce), they presented a lower concentration. The situation was similar in Western Greece, where the companies are mainly located in the Southern areas of Kalavryta (265), Ancient Olympia (268), and Zacharo (275). Follow the northernmost areas of Aktio Vonitsa (259) and Xeromero (274).

\subsubsection{Creative Industries in Apulia and in Western Greece}

This sector includes companies operating in the following subsectors: Communication and branding; Design; Architecture.

Table 3 shows the activities that in both Regions enroll the highest number of active enterprises. 


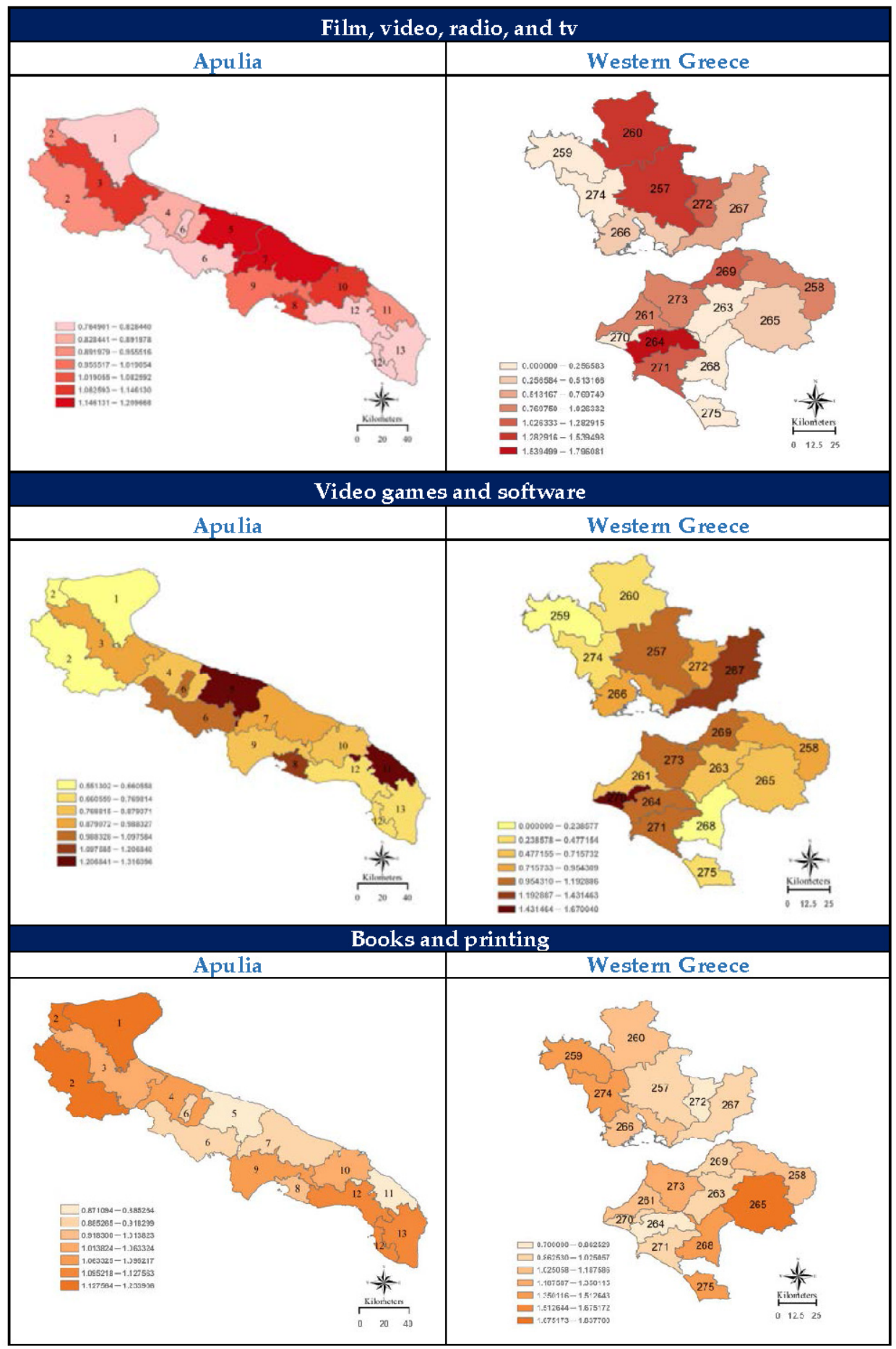

Figure 1. Regional specialization in the Cultural Industries sector. Apulia: 1-Gargano; 2-Monti Dauni; 3-Tavoliere; 4-Puglia Imperiale; 5-Città Metropolitana; 6-Alta Murgia; 7-Murgia Dei Trulli; 8-Magna Grecia; 9-Gravine Tarantine; 10-Brindisi; 11-Lecce; 12-Arco Ionico; 13-Serre Salentine. Western Greece-ACHAIA: 258—Aigialeia; 263-Erymanthos; 265-Kalavryta; 269Patras; 273-West Achaea; AITOLOKARNANIA: 257-Agrinio; 259-Aktio Vonitsa; 260-Amfiloxia; 266-Mesollogi; 267-Nafpaktia; 272-Thermo; 274-Xeromero; ILEIA: 261—Andravida-Kyllini; 264-Ilida; 268-Ancient Olympia; 270—Pineios; 271-Pyrgos; 275-Zacharo. Source: TRACES D3.1 deliverable. 
Table 3. Cross-border specialization in the Creative Industries sector.

\begin{tabular}{lcl}
\hline \multicolumn{1}{c}{ Subsectors } & NACE Code & \multicolumn{1}{c}{ Activities } \\
\hline \multirow{2}{*}{ Communication and branding } & 70.21 & Public relations and \\
& 73.11 & communication activities \\
\hline Design & 74.10 & Advertising agencies \\
\hline Architecture & 71.11 & Specialized design activities \\
\hline
\end{tabular}

Figure 2 reports the GIS maps of the mapped enterprises in these subsectors, offering a visual representation of their localization.

Companies working in these subsectors in Western Greece clearly showed the tendency to concentrate around Patras (269), the capital city of the Region, the third-largest city of Greece, behind Athens and Thessaloniki, and one of the main industrial and commerce centers in Greece.

In Apulia, we observed different location patterns. While Communication and branding activities were mainly located around the biggest cities of the Region (Bari- 5 and Lecce-1), the Design and Architecture activities were mainly located in the Southern and the Northern areas, respectively. Such evidence, together with the direct knowledge of the authors, suggests further investigations on the hypothesis that the localization of companies in these subsectors may depend on vocational factors rather than on a favorable institutional environment.

\subsection{Entrepreneurial Dimension of CCIs in the Investigated Areas}

Both in Apulia and Western Greece, cultural and creative companies showed common features in terms of entrepreneurial structure and challenges to operate and to develop.

CCIs were mainly small-sized enterprises in the form of individual companies $(30.70 \%)$ or associations, cooperatives, and social enterprises $(26.32 \%)$. The private capital company form was adopted by the $20.18 \%$ of investigated CCIs, mainly operating in the Film, Videogames and Music sectors.

In $86.84 \%$ of the observed cases, the workforce consisted of no more than 10 employees. On average, in such companies, there were no more than three permanent employees.

Going deeper in their entrepreneurial dimension, the following subsections showed the main relevant statistics resulting from the focus groups, organized in the six areas of investigation: access to finance, access to the market; IPR; entrepreneurial training and skills; access to innovation; cooperation. Results reflect the most common response across the subsectors ${ }^{1}$.

\subsubsection{Access to Finance}

Focus groups highlighted that in these territories, CCIs face the major challenges of undercapitalization $(72.83 \%$ of respondents-92 out of $114-$ declared that the share of risk capital is under $30 \%$ of the total investment, most of them not reaching the $10 \%$ ) and the difficulty to obtain third party financing sources $(25.60 \%)$, especially on the side of public institutions. Only $22.81 \%$ of the interviewed companies obtained public funds to finance their activity, and among them, the $80.77 \%$ for a share not exceeding the $10 \%$; companies mainly use personal guarantees to secure their debts $(42.98 \%)$. In this regard, the main obstacle to access public grants results from the time-consuming procedures for public incentives $(24.64 \%)$. Another critical point lies in the difficulty of giving the banking system proof of the potential economic value that they are able to generate. In fact, the risk aversion from financial institutions is another obstacle frequently reported $(16.43 \%)$.

To complete the picture, a general lack of culture and skills related to financial planning and management comes into play. The $52.63 \%$ of companies do not do any financial planning, and, among those who use planning $(47.37 \%), 70.37 \%$ plan at one year mostly without specialist support. 


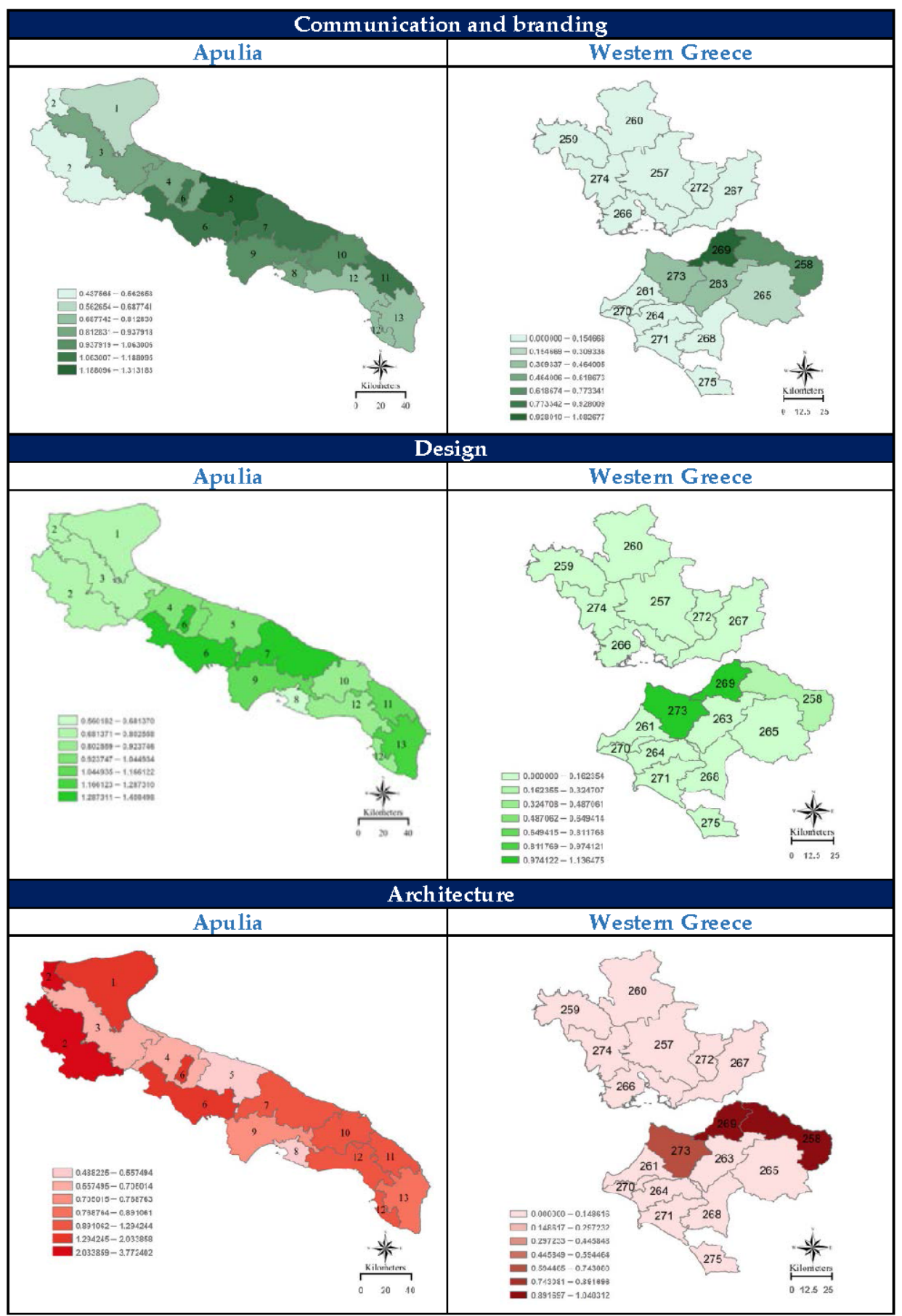

Figure 2. Regional specialization in the Creative Industries sector. Apulia: 1-Gargano; 2-Monti Dauni; 3-Tavoliere; 4-Puglia Imperiale; 5-Città Metropolitana; 6-Alta Murgia; 7-Murgia Dei Trulli; 8-Magna Grecia; 9-Gravine Tarantine; 10-Brindisi; 11-Lecce; 12-Arco Ionico; 13-Serre Salentine. Western Greece-ACHAIA: 258—Aigialeia; 263-Erymanthos; 265-Kalavryta; 269Patras; 273-West Achaea; AITOLOKARNANIA: 257-Agrinio; 259-Aktio Vonitsa; 260-Amfiloxia; 266-Mesollogi; 267-Nafpaktia; 272-Thermo; 274-Xeromero; ILEIA: 261-Andravida-Kyllini; 264-Ilida; 268-Ancient Olympia; 270-Pineios; 271-Pyrgos; 275-Zacharo. Source: TRACES D3.1 deliverable.

\subsubsection{Access to Market}

Lack of funds was the most significant issue that prevented CCIs from accessing the broad market. Limited knowledge of how to run a business comes up as well among the 
main obstacles. Figure 3 shows the complete ranking results about the most important business-related challenges when starting a company in the CCs.

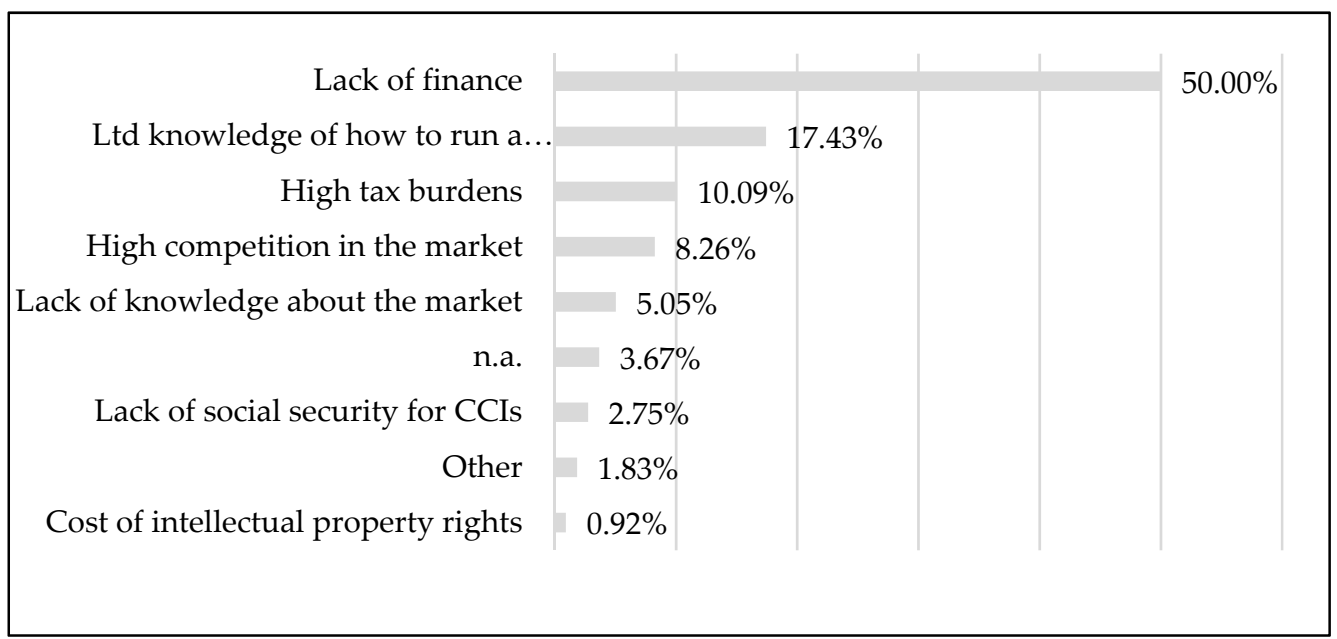

Figure 3. Business-related challenges when starting a company in the CCs. Ranking results Source: Authors elaboration on data collected and shown in TRACES D3.1 deliverable.

In this regard, it emerged that having a strategic vision, leadership, and communication skills were the most relevant managerial factors supporting the growth of the companies, as shown in Figure 4; while the cost of labor and the cost to access finance were the most relevant factors affecting it in Apulia (26.25\% high relevance) and in Western Greece (32.35\% high relevance), respectively.

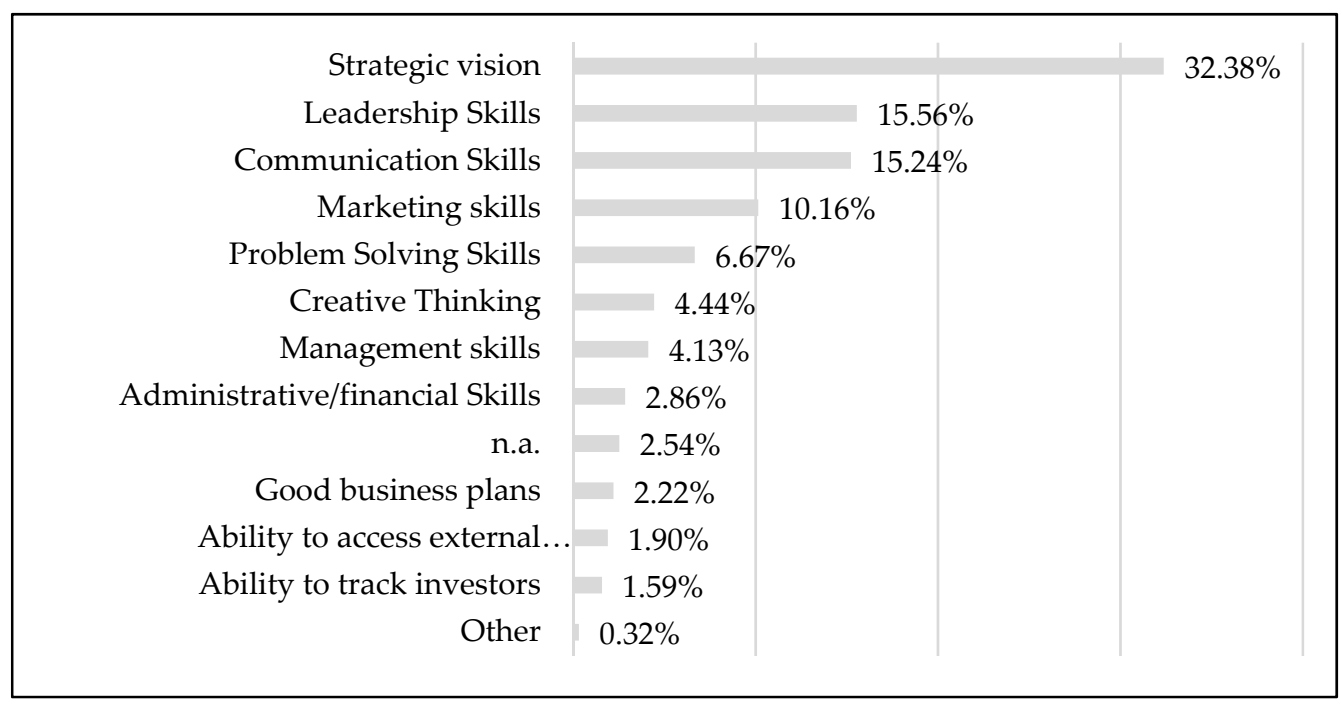

Figure 4. Managerial factors that support the growth of CCIs. Ranking results Source: Authors elaboration on data collected and shown in TRACES D3.1 deliverable.

Moreover, CCIs suffered a strong price competition, which represents the most important entry barrier at the National level $(45.96 \%)$ in both territories. Furthermore, it seems that they found it hard to catch opportunities related to product diversification (34.21\%), while their presence on foreign markets suffers from the nature of the product $(24.56 \%)$, as well as from financial impediments $(11.40 \%)$ and management and control difficulties $(11.40 \%)$. Talking about technological development, the collected information showed that CCIs made little use of ICT tools and solutions, as they have little knowledge on how to exploit the potential inherent in digital management for business purposes (36.84\%). 


\subsubsection{IPR}

Concerning IPR (Intellectual Property Rights), only a few companies appeared keen to protect their products $(21.93 \%)$. Therefore, we can infer a very poor knowledge of this subject, thus considering that $52.63 \%$ never received advice on it. Strategically, companies highlighted the need for laws and services to curb the illegitimate reuse (26.32\%); improving knowledge (17.54\%); allowing greater accessibility to be able to share and freely access existing contents as a means of unlocking the potential benefits that this can offer (17.54\%).

\subsubsection{Entrepreneurial Training and Skills}

Figures 5 and 6 show the ranking results about the relevant critical skills for success and the most important factors in supporting companies in the CCs, respectively. These data give important information about the opportunities that companies are demanding in these territories.

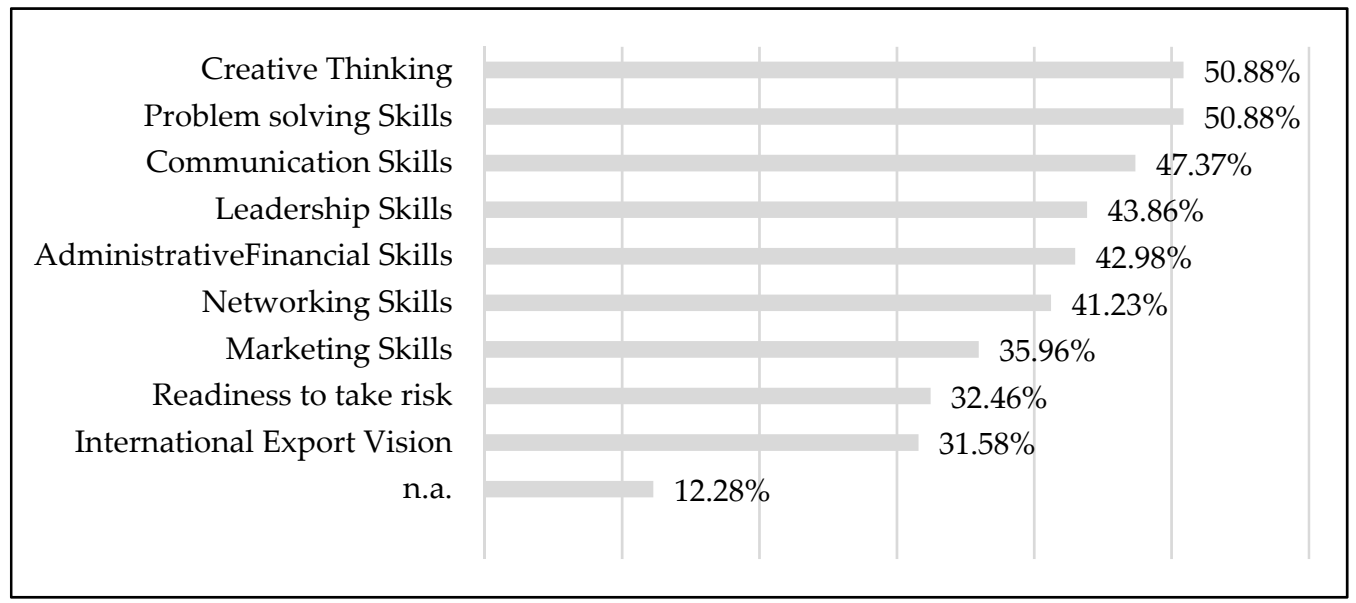

Figure 5. Critical entrepreneurial skills for CCIs success. Ranking results. Source: Authors elaboration on data collected and shown in TRACES D3.1 deliverable.

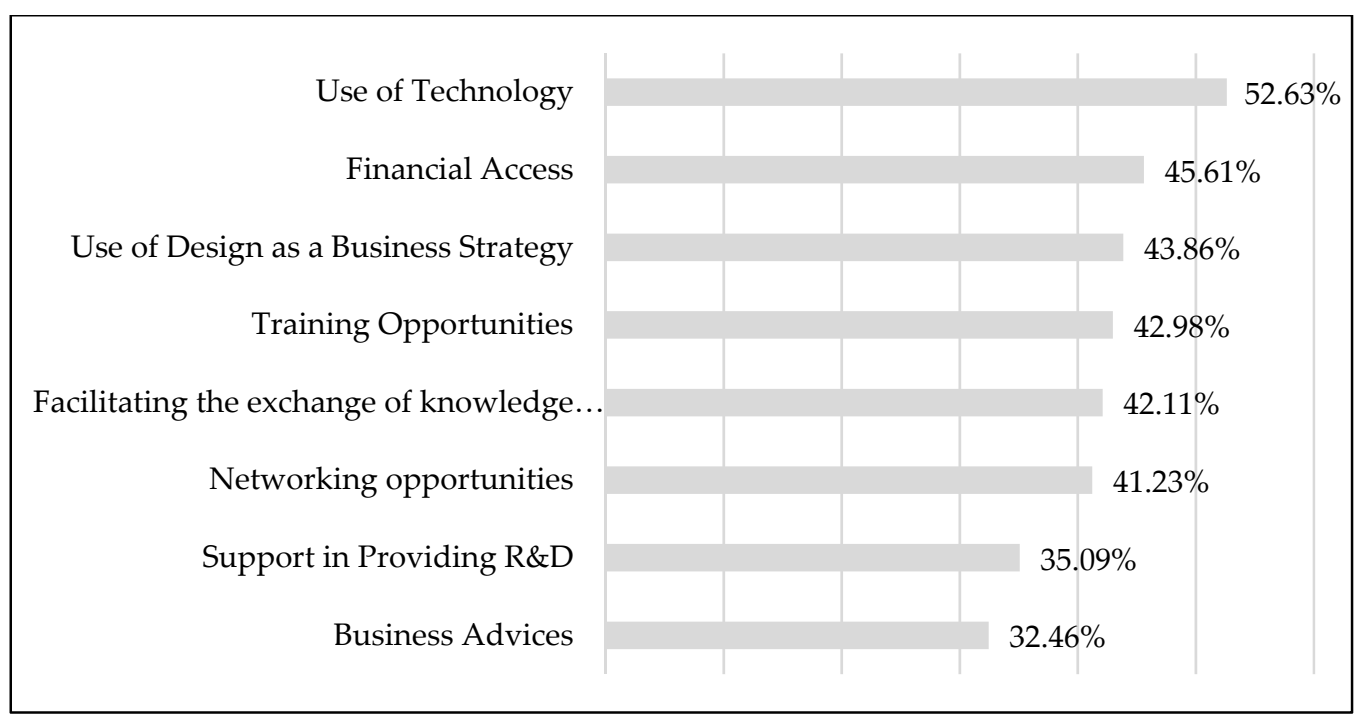

Figure 6. Factors supporting CCIs. Source: Authors elaboration on data collected and shown in TRACES D3.1 deliverable.

The majority of the participating enterprises believe that the development of advice and support centers specifically for the creative and cultural services is quite or much needed $(78.07 \%)$. 


\subsubsection{Access to Innovation}

With regard to research and innovation, interviewed companies gave some important insights on how, what, and why they access innovative processes. Firstly, the most relevant sources of knowledge are individual knowledge sharing (55.43\%) and open information sources $(18.48 \%)$.

They stated that creativity and soft innovation are the most predominant $(42.02 \%)$ followed by technological innovation $(29.41 \%)$, while hidden innovation (such as innovative processes, new organizational models, or new business models) is less important (6.72\%). The aim behind innovation activities was mostly to match users' demands $(35.88 \%)$ and to gain efficiency in service delivery $(31.30 \%)$. Innovating for social improvements came at the third level with $17.56 \%$. In general, $68.04 \%$ of respondents ( 97 out of 114 ) had product innovation which, in the case of the Apulian companies, has been mainly developed in cooperation with other enterprises $(63.64 \%)$, while it has been made by themselves in the most Greek ones (63.64\%).

About the role of CCIs in being drivers of creativity and innovation in other sectors of the economy (open innovation), companies believe that it is necessary:

- To strengthen the links between academia, knowledge institutes, and CCIs (27.50\%);

- To make use of rapid communication (24.17\%);

- To strengthen the links between CCIs and businesses in other sectors $(22.50 \%)$.

\subsubsection{Cooperation}

In the opinion of the interviewed companies, cooperation can mainly serve as a source of innovation through the exchange of good practices (49.28\%) and to take advantage of mutually shared resources $(17.87 \%)$.

The survey showed that companies do usually cooperate with other enterprises. In particular, $48.70 \%$ of the interviewed companies cooperate with enterprises operating in the same sector, while $28.70 \%$ of them cooperate with enterprises in different sectors. The type of their cooperation is based on formal (51.69\%) or non-formal agreements (48.31\%).

Regarding the kind of difficulties faced in operating networks, Figure 7 shows the ranking of the main collected reasons, which prevent them from starting networking.

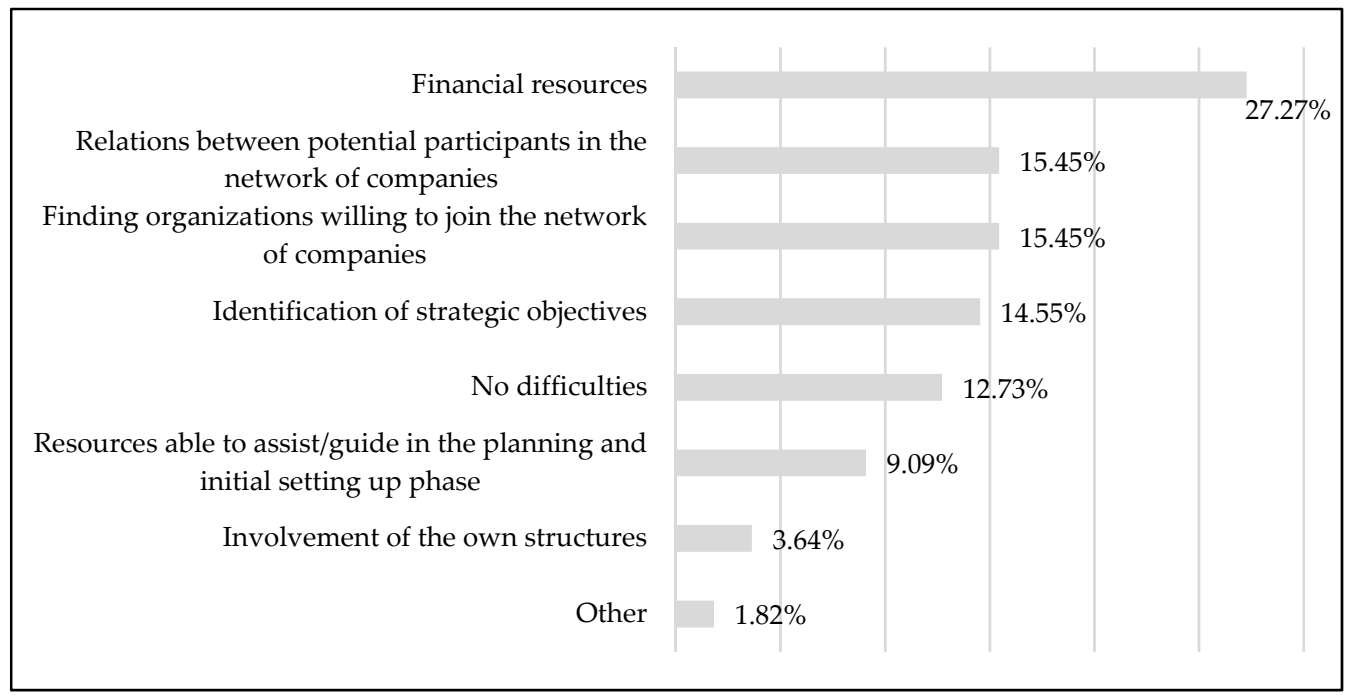

Figure 7. Difficulties to join networks. Ranking results. Source: Authors elaboration on data collected and shown in TRACES D3.1 deliverable.

Finally, as far as it concerns the motivation in networking, the participation of the majority of companies was both defensive (stay on the market/contain the costs) and offensive impactful (innovation, to penetrate a new market) $(58.43 \%$ ), while for the $23.60 \%$ of them it had mostly an offensive aim. 


\subsection{CCIs Common Challenges to Sustainability}

The preliminary understanding described in the above subsections were discussed with more than $400 \mathrm{CCIs}$ and professionals from various geographical zones in both Regions during 22 thematic workshops held according to the World Café methodology in order to assess, among the different issues raised in the focus groups, the most common determinants of CCIs sustainability.

Figure 8 summarizes the common challenges to sustainability assessed by the investigated enterprises.

\begin{tabular}{|l|l|}
\hline Innovation \& Internationalization & Marketing \& Communication \\
- Lack of qualified human capital & - Difficulty in organizing a sales network \\
- Limited access to technology & - Poor ability to understand the market and \\
- Ignorance of Intellectual Property (IP) & define sponsorship, co-branding, partner- \\
rights/procedures & ship and licensing activities \\
- Expensiveness of and limited access to heavy & - Inefficient communication plans \\
equipment & - Inconsistent and unprofessional social me- \\
- Difficulty to access foreign markets & - Pia strategies \\
- Prevalence of locally-based actions & - Difficult approach to media (newspapers, \\
- No technology transfer options & magazines, journalists) \\
- Limited use of e-commerce platforms & \\
\hline Finance and access to credit & Management and business \\
- Bureaucracy & organization \\
- Difficulty to provide the necessary & - Lack of an entrepreneurial culture \\
guarantees to obtain funds from banks & - Poor leadership and managerial skills \\
- Inability to find sponsorship & - Inability to cooperate/coordinate \\
- Difficulty to approach large corporations for & - Difficulties in volunteers' management \\
socially responsible investing actions & - Ignorance of fiscal/legal procedures \\
- Not legally recognized entities & \\
- Inability to raise EU/regional funds & \\
\hline Spaces & Public Administration (PA) and legal \\
- Absence of physical and virtual spaces for & system \\
creative entrepreneurs & - Lack of dialogue between cultural \\
- Difficulty in obtaining authorization from & networks and PA \\
Public Administrations (PA) to implement & - Precarious jobs \\
public actions. & - Lack of information from regional and \\
- Lack of spaces with large capacity and/ or & municipal offices \\
places suitable for big events and exhibitions & - PA representatives' old-fashioned mind set \\
- Abundance of amateurs' atelier & in conceiving and providing services in the \\
- Shortage of spaces to work and create & cultural sector \\
& - No physical nor digital portal for direct \\
communication with PA \\
\hline
\end{tabular}

Figure 8. CCIs common challenges to sustainability. Source: TRACES D3.2 and D2.5 deliverables.

\section{Discussion}

In this section, a discussion of the research results is presented in response to the main research questions addressed in the paper and in the light of the reviewed literature described in Section 1.

Regarding the first research question: What are the main determinants, which CCIs consider crucial for their sustainability in these Regions? It follows a summary of the main determinants, which in the investigated areas seem to obstacle the business sustainability of CCIs.

As already debated in the existing literature, both organizational and location factors can be observed, exerting mutual influence in some respects.

On the organization level, two macro determinants can be identified; both of them are closely related to the interdisciplinary and intangible nature of CCIs' activities, as well as to the cultural and creative entrepreneur mindset and attitude (Borisova 2018; Lazzaro 2018; Madgerova and Kyurova 2019).

The first macro determinant relates to CCIs capability to access finance. Even if the funding needs vary according to different parameters, ranging from the development stage, the type of sector and the working mechanisms, the type of activity, and the project-based structure (KEA European Affairs 2010), the funding mix of the interviewed companies relies predominantly on their own resources and public support. It results in the main hindrance to create a sustainable economic model for their activity in the long term. The 
collected data show that the majority of companies working in the CCs in these Regions are micro and small organizations suffering the challenge of undercapitalization and the difficulty of obtaining third-party financing sources. Self-financing is the most important source of finance to start up, scale-up and access the broad markets; they thus require external funding that they find it hard to raise.

Access to external finance is difficult for different reasons.

Regarding the public funding, which is the main available source they use for cashflow needs, from the participatory assessment, it emerges that the existing tools are often inadequate in supporting the CCIs financial needs. In this regard, the main detected reasons are:

- The administrative and legal procedures to run to obtain the grants are time-consuming, and highly bureaucracy demanding;

- The entry requirements foreclose the access to CCIs operating in the form of social enterprises or as freelancers;

- Actual grant tools do not include soft innovation as an eligible activity for funding; they usually are project-led, short-term with the disbursement of the sums after the conclusion of the financed activity, thus forcing companies to find liquidity elsewhere;

- Public micro-credit tools do not usually contemplate the CCIs NACE codes.

As far as it concerns access to private funding, such as bank credit or equity finance (i.e., business angels, venture capital, etc.), the main challenge reported during the participatory meetings with local CCIs in both Regions relates to the risk aversion from financial institutions, as well as private investors. The reluctance to finance cultural and creative entrepreneurs mainly depends on the low levels of mutual understanding. On the one hand, financial institutions lack risk assessment protocols that take in due account the specificities of the cultural and creative business structure, particularly the dependence on intangible assets providing few or no capital release as collateral for credit risk, as well as the complexity of their value chain. On the other hand, creative people lack skills for business planning and financial management and language to meet the finance sector requirements.

This latter aspect leads to discuss the second macro determinant of CCIs sustainability found in this research: CCIs entrepreneurial mindset and management capability.

In this regard, most of the responses, collected through the focus groups and the participatory meetings, deal with a general lack of entrepreneurial culture and management skills in various fields: financial management and corporate finance strategies, marketing and communication, innovation and internationalization, IPR management, networking and so on. Artists and creative people and talents do not understand, sometimes they refuse to accept, the business and market languages, and at the same time, they lack financial resources to hire qualified staffing to support them in running their activities. This leads CCIs to decision-making processes driven by passion, the symbolic value of their products, artistic expression, and short-term orientation, rather than being inspired by administrative rationality and management control tools. CCIs in the investigated areas are aware of this, and they strongly demand more training opportunities.

Both the abovementioned determinants are not a novelty in the literature, acknowledging the potential and needs of CCIs in other contexts (i.e., HKU 2010; KEA European Affairs 2010; Executive Agency for Small and Medium-sized Enterprises of the European Commission 2016). However, the in-depth knowledge of CCIs operating in these specific contexts contributes to a better understanding of the cause-effect mechanisms, upon which building up a dedicated, supportive policy.

Considering the location factors, it can be reasonably affirmed that when the focus is a peripheral area, the spatial dynamics in the distribution of CCIs in the territory do not change. At this scale, results confirm the general location patterns observed in previous studies focusing on big urban agglomerates. In the periphery, CCIs also tend to be concentrated in areas where they can find the ideal conditions for start-up and growth, generally in areas most populated or in industrial and commercial centers in the Region. 
This is clearly observable for creative industries and for production-related industries such as in the Videogames and software and Film, video, radio, and TV subsectors. Some exceptions are observable too, such as the location patterns of companies specialized in book and printing activities or in design and architecture services, even if the available data do not allow to understand the factors behind the specific pattern, requiring more in-depth research.

However, regardless of the specific localization in the center or in the periphery, companies working in CCs in Apulia and in Western Greece agreed upon specific environmental factors preventing them from sustaining their businesses growing them. The lack of adequate infrastructures, such as co-working and exhibition spaces, as well as the local administrative culture, make the institutional environment not supportive of their sustainability. Figure 8 clearly shows how the relationship with the public administrations at the local level is subject to recurrent complaints in terms of lack of dialogue, inadequate competencies of public officers to deal with creative minds and services, lack of customized services and tools to support CCIs, bureaucratic mind-set. In these regions, above all in Western Greece, the actual public policies to support entrepreneurship seem more suitable for supporting traditional businesses in the industrial sectors, posing de facto important barriers to CCIs in accessing the available policy tools. In this regard, Apulia is further ahead of Western Greece, since regional public authorities started more than 15 years ago to implement dedicated policies, recognizing the potential of the sector for tourism and urban regeneration purposes and its peculiarities compared to the traditional ones. Here, the main public intervention aimed at supporting regional CCIs according to a grant approach, ensuring them the sustainability of the current operations. At the same time, another policy aim is to strengthen the visibility of the sector at the national and international level, especially in the Music, Theatre and Film branches (i.e., through the regional branches Teatro Pubblico Pugliese and Apulia Film Commission), as well as to enhance the excellence of regional interest for tourism attractiveness purposes (i.e., Fondazione Notte della Taranta, Fondazione Paolo Grassi, Lirico Sinfonica Petruzzelli) ${ }^{2}$. All in all, the interviewed CCIs expressed further needs that the existing policies do not address.

The participatory assessment of the CCIs needs to survive and grow gave important results in response to the second research question: What kind of support do they need to survive, develop and benefit territories?

The overall picture of CCIs sustainability emerging from this research suggests the need for dedicated local policies in Apulia and Western Greece Regions able to address the specific features and requirements of CCIs according to a tailored approach in order to support an economically sustainable operation of these enterprises and thus the local development. This does not mean that the type of interventions should be diverse compared to types of economic development support common to generic business support initiativesproviding workspace, training, networking, loans, business management skills, access to technology, and so on. The adoption of a tailored approach implies that these types of intervention should acknowledge the diverse and specific business models, operational structures, and legal forms of the various enterprises populating the CCs, in accessing the available supportive tools.

Just to mention the most debated and acknowledged features, which require different attention and treatment, compared to non-cultural-creative enterprises:

- The survival and development of CCIs imply an economic problem that is the funding needs. In particular, some types of enterprises operating in this sector, such as performing arts, cannot rely only on private contributors (Baumol and Bowen 1965). Accessing to alternative finance sources is a context depending factor, and it is impossible to define a "one size fits all" financing support model (KEA European Affairs 2010);

- Management and performance practices should be aligned to the goals and mission of CCIs (Byrnes 2009; Zan 2006), and creativity needs to be balanced to productivity. Management accounting is often accused of fostering the latter at the expense of the former (Hopper and Bui 2016). 
Then, policies for developing CCIs should be designed accordingly, and public authorities should equip themselves with ad hoc information systems, grasping tailored information about local CCIs entrepreneurial dynamics, attitudes, and needs.

\section{Conclusions}

The paper had the objective to explore the main determinants that affect the CCIs capacity to result in economically sustainable enterprises in two European peripheral areas: Apulia, which is a region in Southern Italy, and in Western Greece, one of the thirteen administrative units of Greece. This exploration has been conceived as instrumental in understanding what kind of policy could better support CCIs survival and development in these areas.

To this end, we used an end-user perspective, with the support of a qualitative analysis that has been structured in order to firstly map the common regional specializations in the field and then to deepen the entrepreneurial dimension and business sustainability of the mapped enterprises. Moreover, we discussed the preliminary research results according to a participatory approach, involving more than 400 CCIs and professionals located in various geographical zones of both Regions. Thus, the results reflect the main challenges and needs which CCIs are actually facing and demanding to strive in being economically sustainable enterprises in these territories.

As far as concern local policy-making, the collected evidence suggests that public policies in place in both territories to support CCIs do not fully meet the detected needs, albeit with different degrees in Apulia and in Western Greece. Generally speaking, the type of support which CCIs are asking for does not differ from the traditional business support tools/schemes, as also Foord'study (Foord 2008) found for other territories. Rather, CCIs highlighted their inadequacy, as they are not tailored, not taking into account their organizational and business peculiarities.

From this point of view, the paper contributes to a better understanding of policymaking for CCIs, suggesting the evidence-based and participatory approach as a useful methodology to customize the generic business support initiatives. Moreover, our results strengthen Pratt's position (Pratt 2009, 2012) on the fact that CCIs require dedicated policymaking; thus, "copying" or "one-size-fits-all" schemes/approaches might not work in this field.

On the theoretical level, this paper does not claim to deal with the current scientific debate in the cultural policy or the economic geography studies addressing the topic of cultural-led development, although the paper slightly dealt with some related aspects. However, in this regard, it encourages, albeit on the basis of mere intuitions raising from the research process, to increase contextual research in peripheral areas since it can offer ground for novel insights on CCIs local patterns.

Rather, it would contribute to the cultural management literature.

As far as concerned the current debate on the addressed topic, as already mentioned in the previous section, our results outline once more how determinant is the CCIs capability to access finance and the CCIs entrepreneurial mindset and management capability, both exerting mutual influence in some respects.

These findings are not a novelty in the literature acknowledging the potential and needs of CCIs in other contexts (i.e., HKU 2010; KEA European Affairs 2010; Executive Agency for Small and Medium-sized Enterprises of the European Commission 2016). However, the in-depth knowledge of CCIs operating in the investigated areas contributes to a better understanding of some cause-effect mechanisms, suggesting directions for future research agenda. In this regard, we can outline the need for robust research at least in the following areas:

- Cash-flow dynamics in relation to different business models, also considering the current digital transformation, to identify the most adequate internal and external financial tools; 
- 'Creative' accounting that is dedicated tools, procedures, and accounting languages which cultural and creative entrepreneurs could easily adopt for cost management control and account for investment readiness;

- 'Creative' managerial education and training, as far as concern the dedicated design and development of disciplinary contents and pedagogy which can better address the mindset, way of doing and learning of cultural and creative people.

From a methodological point of view, the research approach may be considered a novelty in the field in some respects. As far as we know, there is no other study focusing on the addressed geographical zone. Moreover, focusing on common cultural and creative activities across two different countries, our results are independent of the Country's macro (institutional, political, economic, and socio-cultural)-environment influence on CCIs sustainability. Furthermore, it used the participatory approach to assess and validate the focus group's results, so involving in the research process other CCIs located in various geographical zones of both Regions. Thus, the results can be considered to have a higher degree of robustness and generalization than other empirical studies, despite deriving from qualitative analysis and retaining the typical limitations of such research methodologies. Finally, we are aware that such type of investigation is too expensive and hardly replicable without solid financial support. Our hope is that the European Union will continue in the future to believe in the value of research to better serving policy-making and developing new knowledge and practice for the benefit of the sector.

Author Contributions: Conceptualization, methodology, formal analysis and writing-review and editing are the result of the joint effort of the authors. Regarding the writing-original draft preparation: F.I. contributed to Sections 1, 3.1, 3.3 and 5; R.F. contributed to Section 3.2; S.A. contributed to Section 2. R.F. and S.A. jointly contributed to Section 4. All authors have read and agreed to the published version of the manuscript.

Funding: This research is part of a funded project by Cooperation Programme "Interreg V-A GreeceItaly" (EL-IT) 2014-2020, subsidy contract No. I1/1.2/26. Special acknowledge goes to the Joint Secretariat of the Program, to Gianfranco Gadaleda and Tina Ranieri, for their kind authorization to use the project data.

Institutional Review Board Statement: Not applicable.

Informed Consent Statement: Not applicable.

Data Availability Statement: Raw data supporting the findings of this study are available from the corresponding author, Francesca Imperiale, upon reasonable request.

Conflicts of Interest: The author declares no conflict of interest. The funders had no role in the design of the study; in the collection, analyses, or interpretation of data; in the writing of the manuscript, or in the decision to publish the results. The collection of data was made with the collaboration of Chamber of Achaia, Hellenic Management Association and Distretto Puglia Creativa, partners of the Interreg Greece-Italy project TRACES. 


\section{Appendix A}

\begin{tabular}{|c|c|c|c|}
\hline Sector & Subsectors & $\begin{array}{l}\text { NACE } \\
\text { Code }\end{array}$ & Activities \\
\hline \multirow{31}{*}{$\begin{array}{l}\text { Cultural } \\
\text { Industries }\end{array}$} & \multirow{7}{*}{$\begin{array}{l}\text { Film, video, radio } \\
\text { and tv }\end{array}$} & 59.11 & $\begin{array}{l}\text { Motion picture, video and television programme } \\
\text { production activities }\end{array}$ \\
\hline & & 59.12 & $\begin{array}{l}\text { Motion picture, video and television programme post- } \\
\text { production activities }\end{array}$ \\
\hline & & 59.13 & $\begin{array}{l}\text { Motion picture, video and television programme } \\
\text { distribution activities }\end{array}$ \\
\hline & & 59.14 & Motion picture projection activities \\
\hline & & 60.10 & Radio broadcasting \\
\hline & & 60.20 & Television programming and broadcasting activities \\
\hline & & 77.22 & Renting of video tapes and disks \\
\hline & \multirow{5}{*}{$\begin{array}{l}\text { Videogames and } \\
\text { software }\end{array}$} & 32.40 & Manufacture of games and toys \\
\hline & & 58.21 & Publishing of computer games \\
\hline & & 58.29 & Other software publishing \\
\hline & & 62.01 & Computer programming activities \\
\hline & & 63.12 & Web portals \\
\hline & \multirow{5}{*}{ Music } & 18.20 & Reproduction of recorded media \\
\hline & & 26.40 & Manufacture of consumer electronics \\
\hline & & 32.20 & Manufacture of musical instruments \\
\hline & & 47.63 & Retail sale of sporting equipment in specialised stores \\
\hline & & 59.20 & Sound recording and music publishing activities \\
\hline & \multirow{14}{*}{ Books and printing } & 18.11 & Printing of new spapers \\
\hline & & 18.12 & Other printing \\
\hline & & 18.13 & Pre-press and pre-media services \\
\hline & & 18.14 & Binding and related services \\
\hline & & 47.61 & Retail sale of books in specialised stores \\
\hline & & 47.62 & $\begin{array}{l}\text { Retail sale of new spapers and stationery in specialised } \\
\text { stores }\end{array}$ \\
\hline & & 58.11 & Book publishing \\
\hline & & 58.13 & Publishing of new spapers \\
\hline & & 58.14 & Publishing of journals and periodicals \\
\hline & & 58.19 & Other publishing activities \\
\hline & & 63.91 & News agency activities \\
\hline & & 74.20 & Photographic activities \\
\hline & & 74.30 & Translation and interpretation activities \\
\hline & & 90.03 & Artistic creation \\
\hline \multirow{6}{*}{$\begin{array}{l}\text { Creative } \\
\text { Industries }\end{array}$} & Architecture & 71.11 & Architectural activities \\
\hline & \multirow{4}{*}{$\begin{array}{l}\text { Communication } \\
\text { and } \\
\text { branding }\end{array}$} & 70.21 & Public relations and communication activities \\
\hline & & 73.11 & Advertising agencies \\
\hline & & 73.12 & Media representation \\
\hline & & 82.30 & Organisation of conventions and trade shows \\
\hline & Design & 74.10 & Specialised design activities \\
\hline \multirow{4}{*}{$\begin{array}{l}\text { Performing } \\
\quad \text { Arts }\end{array}$} & \multirow{4}{*}{$\begin{array}{l}\text { Performing arts, } \\
\text { recreation } \\
\text { activities, } \\
\text { conventions and } \\
\text { trade shows }\end{array}$} & 85.52 & Cultural education \\
\hline & & 90.01 & Performing arts \\
\hline & & 90.02 & Support activities to performing arts \\
\hline & & 90.04 & Operation of arts facilities \\
\hline \multirow{3}{*}{ Heritage } & \multirow{3}{*}{$\begin{array}{l}\text { Museums, } \\
\text { Libraries, Archives, } \\
\text { Operation of } \\
\text { historical sites and } \\
\text { buildings } \\
\end{array}$} & 91.01 & Libraryand archives activities \\
\hline & & 91.02 & Museums activities \\
\hline & & 91.03 & $\begin{array}{l}\text { Operation of historical sites and buildings and similar } \\
\text { visitor attractions }\end{array}$ \\
\hline
\end{tabular}

Figure A1. Cultural and Creative Industries-Core Sector perimeter according to the Symbola's methodology.

\section{Notes}

1 The complete descriptive statistics and figures for each investigated Region are included in the TRACES D3.1 deliverable. The paper reports only some statistics which the authors consider relevant in relation to the research questions, the clarity of presentation and the space saving.

2 On the Apulia policies for CCIs see https:/ / www.regione.puglia.it/web/turismo-e-cultura (accessed on 26 July 2021). 


\section{References}

ArtENprise. 2016. Entrepreneurial Competences for Artists and Cultural Operators. European Study Report. Proj. No: 2016-1-ES01-KA202025606. Available online: https:/ / www.artenprise.eu/full-report/ (accessed on 20 August 2021).

Avdikos, Vasilis. 2014. The Cultural and Creative Industries in Greece. Athens: Epikendro Publications.

Avdikos, Vasilis, Martha Michailidou, George-Michael Klimis, Lefteris Gaitanidis, Panayiotis Nikolopoulos, Panayiotis Drakakis, and Eleni Kostopoulou. 2017. Mapping the Creative and Cultural Industries in Greece. Athens: Regional Development Institute-Panteion University, Hellenic Republic-Ministry of Culture and Sports.

Baumol, William J., and William G. Bowen. 1965. On the Performing arts: The Anatomy of Their Economic Problems. The American Economic Review 55: 495-502.

Benhamou, Françoise. 2003. Artists' labour markets. In A Handbook of Cultural Economics. Edited by Ruth Towse. Cheltenham: Edward Elgar Publishing.

Boal-San Miguel, Iván, and Luis César Herrero-Prieto. 2020. A Spatial-Temporal Analysis of Cultural and Creative Industries with Micro-Geographic Disaggregation. Sustainability 12: 6376. [CrossRef]

Boffo, Marco, and Roberto Chizzali. 2015. Quali confini per il settore delle ICC? Lo stato dell'arte della modellistica a livello internazionale e in Italia. In ACTORS Italia. Attrattori culturali per il turismo e l'occupazione nelle regioni del sud Italia. Paris: OECD Publishing, Available online: https://www.oecd.org/cfe/leed/D_ICC_definizione_e_classificazione_Boffo_Chizzali.pdf (accessed on 19 June 2018).

Borisova, Vladia. 2018. Essential Characteristics and Market of the Creative Industries' Product. Economic Alternatives 1: 113-22.

Branzanti, Caterina. 2015. Creative clusters and district economies: Towards a taxonomy to interpret the phenomenon. European Planning Studies 23: 1401-18. [CrossRef]

Byrnes, William J. 2009. Management and the Arts. Oxford: Focal Press.

Caves, Richard E. 2000. Creative Industries. Cambridge: Harvard University Press.

Chapain, Caroline, and Roberta Comunian. 2010. Enabling and Inhibiting the Creative Economy: The Role of the Local and Regional Dimensions in England. Regional Studies 44: 717-34. [CrossRef]

Chapain, Caroline, and Lisa De Propris. 2009. Drivers and processes of creative industries in cities and regions. Creative Industries Journal 2: 9-18. [CrossRef]

Comunian, Roberta, Caroline Chapain, and Nick Clifton. 2010. Location, location, location: Exploring the complex relationship between creative industries and place. Creative Industries Journal 3: 5-10. [CrossRef]

Correa-Quezada, Ronny, Josè Álvarez-García, María De la Cruz Del Río-Rama, and Claudia P. Maldonado-Erazo. 2018. Role of Creative Industries as a Regional Growth Factor. Sustainability 10: 1649. [CrossRef]

Cunningham, Stuart. 2002. From Cultural to Creative Industries: Theory, Industry, and Policy Implications. Media International Australia Incorporating Culture and Policy 102: 54-65. [CrossRef]

De Vaan, Mathijs, Ron Boschma, and Koen Frenken. 2013. Clustering and firm performance in project-based industries: The case of the global video game industry, 1972-2007. Journal of Economic Geography 13: 965-91. [CrossRef]

DeFillipi, Robert J., and Michael B. Arthur. 1998. Paradox in project-based enterprise. California Management Review 40: 125-39. [CrossRef]

Executive Agency for Small and Medium-sized Enterprises of the European Commission. 2016. Boosting the Competitiveness of Cultural and Creative Industries for Growth and Jobs. Luxembourg: Publications Office of the European Union.

European Investment Fund. 2019. Market Analysis of the CCS in Europe. Luxemburg: EIF.

EY. 2015. Cultural Times. The First Global Map of Cultural and Creative Industries. Study on Behalf of the International Confederation of Societies of Authors and Composers (CISAC). Available online: https://en.unesco.org/creativity/files/ culturaltimesthefirstglobalmapofculturalandcreativeindustriespdf (accessed on 30 April 2019).

Falk, Rahel, Hasan Bakhshi, Martin Falk, Wilhelm Geiger, Susanne Karr, Catherine Keppel, Hannes Leo, and Roland Spitzlinger. 2011. Innovation and Competitiveness of the Creative Industries. Vienna: Austrian Institute of Economic Research, Wifo. Available online: https:/ / www.wifo.ac.at/jart/prj3/wifo/resources/person_dokument/person_dokument.jart?publikationsid=41510\& mime_type=application / pdf (accessed on 20 August 2021).

Flew, Terry. 2012. Creative Industries and Urban Development. Creative Cities in the 21st Century. Abingdon: Routledge.

Florida, Richard. 2002. The Rise of the Creative Class: And How It's Transforming Work, Leisure, Community and Everyday Life. New York: Basic Books.

Florida, Richard. 2005. Cities and the Creative Class. London: Routledge.

Fondazione Symbola. 2019. We are Creative in Puglia. Rapporto Sulle Imprese Culturali e Creative in Puglia. Available online: https:/ / www.symbola.net/ricerca/we-are-creative-in-puglia-2019/ (accessed on 15 May 2019).

Foord, Jo. 2008. Strategies for creative industries: An international review. Creative Industries Journal 1: 91-113. [CrossRef]

Galloway, Susan, and Stewart Dunlop. 2007. A Critique of Definitions of the Cultural and Creative Industries in Public Policy. International Journal of Cultural Policy 13: 17-31. [CrossRef]

Gong, Huiwen, and Robert Hassink. 2017. Exploring the clustering of creative Industries. European Planning Studies 25: 583-600. [CrossRef]

Gray, Clive. 2007. Commodification and instrumentality in cultural policy. International Journal of Cultural Policy 13: 203-15. [CrossRef]

Hall, Stuart. 1973. Encoding and Decoding in the Television Discourse. Discussion Paper. Birmingham: University of Birmingham. 
Hall, Peter. 2000. Creative cities and economic development. Urban Studies 37: 639-49. [CrossRef]

Harc, Martina, I. Bestvina Bukvić, and Josipa Mijoč. 2019. Entrepreneurial and Innovative Potential of the Creative Industry. pp. $1562-77$. Available online: https:/ / www.bib.irb.hr/1008980 (accessed on 27 August 2021).

Harvey, David C., Harriet Hawkins, and Nicola J. Thomas. 2012. Thinking creative clusters beyond the city: People, places and networks. Geoforum 43: 529-39. [CrossRef]

Heebels, Barbara, and Irina van Aalst. 2010. Creative clusters in Berlin: Entrepreneurship and the quality of place in Prenzlauer Berg and Kreuzberg. Geografiska Annaler Series B Human Geography 92: 347-63. [CrossRef]

Hesmondhalgh, David, and Andy C. Pratt. 2005. Cultural industries and cultural policy. International Journal of Cultural Policy 11: 1-13. [CrossRef]

HKU. 2010. The Entrepreneurial Dimension of the Cultural and Creative Industries. Utrecht: Hogeschool vor de Kunsten Utrecht.

Hopper, Trevor, and Binh Bui. 2016. Has management accounting research been critical? Management Accounting Research 31: 10-30. [CrossRef]

Jakob, Doreen, and Bas van Heur. 2015. Editorial: Taking Matters into Third Hands: Intermediaries and the Organization of the Creative Economy. Regional Studies 49: 357-61. [CrossRef]

Jeffcutt, Paul, and Andy C. Pratt. 2002. Managing Creativity in the Cultural Industries. Creativity and Innovation Management 11: 225-33. [CrossRef]

Kavousy, Esmaeil, Ali Shahhosseini, Soheila Kiasi, and Fateme T. Ardahaey. 2010. Cultural entrepreneurship strategies in Iran. Serbian Journal of Management 5: 227-41.

KEA European Affairs. 2010. Promoting Investment in the Cultural and Creative Sector: Financing Needs, Trends and Opportunities; Report prepared for ECCE Innovation-Nantes Métropole. Brussels: KEA European Affairs. Available online: https://www.keanet.eu/ wp-content/uploads/access-to-finance-study_final-report_kea-june2010.pdf (accessed on 16 January 2016).

Landry, Charles. 2008. The Creative City: A Toolkit for Urban Innovators. London: Routledge.

Lazzaro, Elisabetta. 2018. Cultural and creative Entrepreneurs. In Culture, Innovation and the Economy. Edited by Biljana Mickov and James E. Doyle. London: Routledge, pp. 33-37.

Lazzeretti, Luciana, and Marilena Vecco. 2018. Creative Industries and Entrepreneurship: Paradigms in Transition from a Global Perspective. Cheltenham: Edward Elgar Publishing.

Lazzeretti, Luciana, Rafael Boix, and Francesco Capone. 2008. Do creative industries cluster? Mapping creative local production systems in Italy and Spain. Industry and Innovation 15: 549-67. [CrossRef]

Leadbeater, Charles, and Kate Oakley. 1999. The Independents Britain's New Cultural Entrepreneurs. London: DEMOS.

Lorenzen, Mark, and Lars Frederiksen. 2008. Why do cultural industries cluster? Localization, urbanization, products and projects. In Creative Cities, Cultural Clusters and Local Economic Development. Edited by Philip Cooke and Luciana Lazzeretti. Cheltenham: Edward Elgar, pp. 155-79.

Madgerova, Raya, and Vyara Kyurova. 2019. Specifics of entrepreneurship in the field of cultural and creative industries. Entrepreneurship VII: 103-23.

McNeilly, Nicole. 2018. Cultural and Creative Spillovers in Europe. A Follow-Up Review. The European Research Partnership on Cultural and Creative Spillovers. Available online: https://ccspillovers.weebly.com/uploads/1/1/8/4/118427712/ccs_summary_2018 .pdf (accessed on 19 November 2019).

O'Connor, Justin. 2000. The definition of the 'cultural industries'. The European Journal of Arts Education 2: 15-27.

O'Connor, Justin. 2010. The Cultural and Creative Industries: A Literature Review, 2nd ed. Creativity, Culture and Education Series; Newcastle upon Tyne: Creativity. First published 2007.

O'Connor, Justin. 2004. 'A special kind of city knowledge': Innovative clusters, tacit knowledge and the 'Creative City'. Media International Australia 112: 131-49. [CrossRef]

Peck, Jamie. 2005. Struggling with the creative class. International Journal of Urban and Regional Research 29: 740-70. [CrossRef]

Porter, Michael E. 1989. The Competitive Advantage of Nations. New York: The Free Press.

Power, Dominic. 2003. The Nordic 'Cultural Industries': A Cross-National Assessment of the Place of the Cultural Industries in Denmark, Finland, Norway and Sweden. Geografiska Annaler Series B Human Geography 85: 167-80. [CrossRef]

Pratt, Andy C. 2009. Policy transfer and the field of the cultural and creative industries: Learning from Europe? In Creative Economies, Creative Cities: Asian-European Perspectives. Edited by Lily Kong and Justin O'Connor. Heidelberg: Springer, pp. 9-23.

Pratt, Andy C. 2010. Creative cities: Tensions within and between social, cultural and economic development: A critical reading of the UK experience. City, Culture and Society 1: 13-20. [CrossRef]

Pratt, Andy C. 2012. The cultural and creative industries: Organisational and spatial challenges to their governance. Die Erde 143: 317-34.

Rantisi, Norma M., and Deborah Leslie. 2015. Significance of higher educational institutions as cultural intermediaries: The case of the École nationale de cirque in Montreal, Canada. Regional Studies 49: 404-17. [CrossRef]

Regional Development Fund of Region of Western Greece. 2018. CREADIS3: Report on Territorial Diagnosis. Regional Development Fund of Region of Western Greece. Available online: https:/ / www.interregeurope.eu/fileadmin/user_upload/tx_tevprojects/ library / file_1551777107.pdf (accessed on 26 July 2021).

Sacco, Pierluigi, Guido Ferilli, and Giorgio Tavano Blessi. 2014. Understanding culture-led local development: A critique of alternative theoretical explanations. Urban Studies 51: 2806-21. [CrossRef] 
Scott, Allen J. 2000. The Cultural Economy of Cities: Essays on the Geography of Image-Producing Industries. London: Sage.

Skoglund, Wilhelm, and Gun Jonsson. 2012. The potential of cultural and creative industries in remote areas. Nordisk Kulturpolitisk Tidskrift 15: 181-91. [CrossRef]

Storper, Michael. 1995. The Resurgence of Regional Economies, Ten Years Later: The Region as a Nexus of Untraded Interdependencies. European Urban and Regional Studies 2: 191-221. [CrossRef]

Symbola, Fondazione per le qualità italiane, and Unioncamere. 2013. Io Sono Cultura. L'Italia della Qualità e Della Bellezza Sfida la Crisi. Roma: Copygraph sas.

Throsby, David. 2001. Economics and Culture. Cambridge: Cambridge University Press.

Tom Fleming Creative Consultancy. 2015. Cultural and Creative Spillovers in Europe: Report on a Preliminary Evidence Review. Available online: https:/ / www.artscouncil.org.uk/sites/default/files/Cultural_creative_spillovers_in_Europe_full_report.pdf (accessed on 12 September 2019).

Tomczak, Paulina, and Krzysztof Stachowiak. 2015. Location patterns and location factors in the cultural and creative industries. Quaestiones Geographicae 34: 7-27. [CrossRef]

Townley, Barbara, Nic Beech, and Alan McKinlay. 2009. Managing in the creative industries: Managing the motley crew. Human Relations 62: 939-62. [CrossRef]

Turok, Ivan. 2003. Cities, clusters and creative industries: The case of film and television in Scotland. European Planning Studies 11: 549-65. [CrossRef]

UNESCO-World Bank. 2021. Cities, Culture, Creativity: Leveraging Culture and Creativity for Sustainable Urban Development and Inclusive Growth. Paris: UNESCO, Washington, DC: World Bank, License: CC BY-SA 3.0 IGO. Available online: https:/ / openknowledge. worldbank.org/handle/10986/35621 (accessed on 7 June 2021).

United Nations/UNDP/UNESCO. 2013. Creative Economy Report. Widening Local Development Pathways. Available online: http:/ / www.unesco.org/culture/pdf/creative-economy-report-2013.pdf (accessed on 26 July 2021).

Wenting, Rik. 2008. Spinoff dynamics and the spatial formation of the fashion design industry, 1858-2005. Journal of Economic Geography 8: 593-614. [CrossRef]

Wenting, Rik, and Koen Frenken. 2011. Firm entry and institutional lock-in: An organizational ecology analysis of the global fashion design industry. Industrial and Corporate Change 20: 1031-48. [CrossRef]

Wu, Weiping. 2005. Dynamic Cities and Creative Clusters. In World Bank Policy Research Working Paper. Washington, DC: World Bank Publications, p. 3509.

Zan, Luca. 2006. Managerial Rhetoric and Arts Organizations. Basingstoke: Palgrave Macmillan. 